\title{
Negligence, Ignorance and the Demand for Liability Insurance
}

\author{
Vickie Bajtelsmit ${ }^{\mathrm{a}}$ and Paul Thistle ${ }^{\mathrm{b}}$ \\ a Department of Finance and Real Estate, Colorado State University, Ft. Collins, CO 80523, USA. \\ E-mail: vickie.bajtelsmit@colostate.edu \\ ${ }^{b}$ Department of Finance, University of Nevada Las Vegas, Las Vegas, NV 89154, USA. \\ E-mail: paul.thistle@unlv.edu
}

This paper considers whether lack of information regarding risk exposures can lead to a demand for negligence liability insurance. We find that, under the uniform negligence rule, such as the "reasonable person" standard used to determine negligence in the U.S. and other countries, the value of information is positive and any demand for liability insurance must come from informed individuals. The necessary and sufficient condition is that good risks find it less costly to be negligent and purchase insurance.

The Geneva Risk and Insurance Review (2009) 34, 105-116. doi:10.1057/grir.2009.4

Keywords: information; tort; moral hazard; screening

\section{Introduction and background}

The law of negligence holds injurers responsible for the damages they inflict on their victims only if they have not met the applicable standard of care. Under U.S. law, the standard usually applied is called the "reasonable person" standard. Under this rule, if the level of care taken is consistent with that which would have been taken by a reasonable person, then there is no liability and the victim bears the full cost of his or her injuries. Thus, if a person takes appropriate care, there is no reason to purchase liability insurance. ${ }^{1}$

The existence of a thriving market for negligence liability insurance, including both personal and commercial lines, implies that the current structure of liability law exposes market participants to some type of risk that can be

\footnotetext{
${ }^{1}$ Brown (1973) shows that risk neutral agents will meet the negligence standard if it is set optimally. Shavell (1982) shows that this implies risk averse agents will not purchase liability insurance.
} 
managed more cost-effectively by purchasing insurance. For some types of negligence, the market for liability insurance is the result of legal (e.g., auto) or contractual (e.g., homeowners) requirements. The markets for other types of negligence liability insurance, such as medical malpractice, professional liability, and commercial general liability insurance, are more difficult to explain since knowledge of the standard of care would imply that every potential injurer could simply meet the standard of care and would never be liable.

Shavell (2000, pp. 171-172), reflecting widely held views, argues that insurance is purchased against risks due to the uncertain operation of the legal system, risks due to momentary lapses in care, and risks due to the negligent behavior of agents. Crocker and Doherty (2000) argue that potential injurers' ignorance about the risks they face may provide a motive for the purchase of liability insurance. They assume that potential injurers can cause either small or large damages in the event of an accident. The legal standard of care is assumed to depend on the size of the damages, that is, on the potential injurers' type. However, Crocker and Doherty assume that potential injurers do not know their type and hence do not know the appropriate level of care to take. In their analysis, potential injurers are allowed to learn their type at zero cost. Thus, potential injurers face a choice between becoming informed and taking appropriate precautions or remaining uninformed and purchasing liability insurance. Crocker and Doherty show that potential injurers may choose to be uninformed. For these rationally ignorant potential injurers, liability insurance allows them to hedge the "classification risk," that is, the risk associated with the unknown cost of meeting the standard of due care.

Crocker and Doherty's work can be viewed as an extension of Shavell's (1992) analysis of the effect of liability law on potential injurers' incentives to become informed about potential risks and to take care. Shavell considers several negligence rules, where liability may depend on both the decision to become informed and the level of care or may depend solely on the level of care. Negligence rules that require or assume optimal acquisition of information lead to optimal acquisition of information and optimal care. Other negligence rules may result in too much or too little information and consequently, in too much or too little care. However, Shavell does not consider the implications for insurance markets.

We examine the issue of whether individuals' ignorance regarding the risks they face can lead to a demand for liability insurance. ${ }^{2}$ Specifically, we analyze

\footnotetext{
${ }^{2}$ Uncertain operation of the courts, momentary lapses in care, and the negligent behavior of agents are all motivations for individuals' and firms' purchases of liability insurance under a negligence rule. The question we address in this paper is whether economic agents' ignorance about risks they face is an additional reason for buying insurance.
} 
models in which, as in Crocker and Doherty, individuals are initially uninformed about their characteristics but have the opportunity to learn about their type, to purchase insurance, and to take care. We consider the uniform negligence rule, where all individuals must meet the same standard of due care (the "reasonable person" standard); this is the dominant negligence standard in the United States. We analyze situations in which individuals are initially uninformed about their probability of having an accident (their risk-type). We also examine the effect of the information disclosure environment, that is, the ability of potential injurers to credibly communicate their risk type and their informed/uninformed status to insurers. We seek to answer two questions. Under what conditions do potential injurers become informed? Whether or not they become informed, under what conditions do potential injurers buy liability insurance?

We find that, under the uniform negligence rule, the value of information is positive, hence, the outcome is the same as if potential injurers were initially informed. Potential injurers whose privately optimal level of care is below the negligence standard will choose to insure. The necessary and sufficient condition is that it is less costly to be negligent and purchase insurance than to be non-negligent.

Since potential injurers can choose to remain rationally ignorant or can choose to learn about the risks they face, our work is related to previous research on endogenous information in insurance markets (Crocker and Snow, 1992; Doherty and Thistle, 1996; Ligon and Thistle, 1996a,b). This earlier work considered pure adverse selection economies, whereas we allow potential injurers to take actions to reduce the probability of loss. Since potential injurers can take actions to reduce loss probabilities, our analysis is also related to the work on "self-protection" (Ehrlich and Becker, 1972). Finally, since insurance coverage and self-protection activities are observable and correlated with potential injurers' type, the problem analyzed here can be viewed on one of endogenous risk classification (Bond and Crocker, 1991).

The next section describes the basic assumptions of the model, defines the negligence rules, and the value of information. The subsequent section analyzes the incentives to become informed and to insure under the uniform negligence standard assuming that individuals do not know their accident probabilities. The final section provides brief concluding remarks.

\section{The basic model}

\section{Assumptions}

The analytical model is an extension of the standard model of accidents in the law and economics literature (e.g., Shavell, 1982, 1987). As in Crocker and Doherty, we assume that accidents are unilateral, that is, only the potential 
108

injurer's care affects the probability of an accident. We also assume the accidents are "between strangers," that is, there is no contractual relationship that the potential victim can use to provide incentives for the potential injurer to take care.

Let $x$ denote the potential injurer's expenditure on accident prevention or "care." Let $p_{G}(x)$ (resp., $\left.p_{B}(x)\right)$ be the probability of an accident when a "good risk" type (resp., "bad risk" type) spends $x$ on care. The probability of an accident is a strictly decreasing, strictly convex function of expenditure on care. The good risk types have a lower accident probability than the bad risk types for any expenditure on care, $0<p_{G}(x)<p_{B}(x)<1$, and have a higher marginal product of care, $p_{G}^{\prime}(x)>p^{\prime}{ }_{B}(x)$. Let $\lambda_{G}$ and $\lambda_{B}$ be the proportions of good and bad risks, where $\lambda_{G}, \lambda_{B}>0$ and $\lambda_{G}+\lambda_{B}=1$. Let $L>0$ be the loss suffered by victims.

An important aspect of the analysis here is that potential injurers do not necessarily know whether they are good risks or bad risks. ${ }^{3}$ However, they do know that they are good risks or bad risks with probabilities $\lambda_{G}$ and $\lambda_{B}$. We use the subscript $I$ to denote potential injurers who are uninformed or ignorant about their risk type. Then uninformed potential injurers estimate their probability of an accident as $p_{I}(x)=\lambda_{G} p_{G}(x)+\lambda_{B} p_{B}(x)$.

Potential injurers have initial wealth $W>L$ and the von NeumanMorgenstern utility function $U(W)$, which is strictly increasing and strictly concave. Potential victims have initial wealth $Y$. We assume potential victims are risk neutral, since this leads to a simple characterization of the liability rule. Individuals know whether they are a potential injurer or a potential victim.

An insurance policy consists of a premium, $\pi$, and an indemnity, $q$, paid in the event the policyholder is liable for a victim's losses. A potential injurer who buys the insurance policy $\left(\pi_{l}, q_{i}\right)$ and expends $x_{i}$ on care therefore has expected utility given by

$$
\begin{aligned}
V\left(\pi_{i}, q_{i}, x_{i}\right)= & \left(1-p_{i}\left(x_{i}\right)\right) U\left(W-\pi_{l}-x_{i}\right) \\
& +p_{i}\left(x_{i}\right) U\left(W-\pi_{i}-x_{i}-L+q_{i}\right)
\end{aligned}
$$

if the individual is negligent and by

$$
V\left(\pi_{i}, q_{i}, x_{i}\right)=U\left(W-\pi_{l}-x_{i}\right)
$$

if the individual is not negligent, for $i=B, G, I$.

We assume that the liability standard is perfectly enforced so that there is no uncertainty in the definition or application of the negligence rule. This implies

\footnotetext{
${ }^{3}$ We can extend the models analyzed here to allow a portion of the potential injurers to be exogenously informed. This does not change any of the results in the paper.
} 


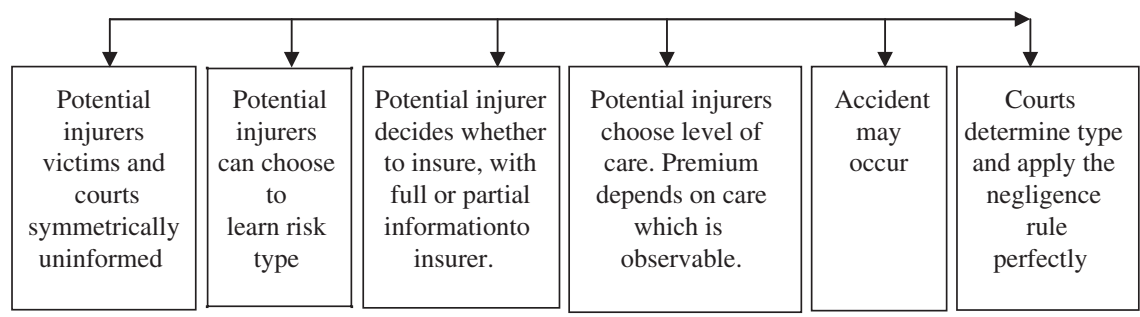

Figure 1. Timing of the model.

that victims, courts, and insurers can perfectly verify both the injurer's type and the injurer's level of care if an accident occurs. Since victims and courts can verify the injurer's care, we assume care is observable. This implies that the insurance premium can depend on the level of care. ${ }^{4}$

We assume throughout that the insurance market is competitive and that insurers earn zero expected profit, given the information they have about policyholders. The zero expected profit constraint is then $\pi_{l}=p_{i}(x) q_{i}, i=B, G, I$. Since the premium is actuarially fair, if potential injurers insure, they will choose full coverage $(q=L)$ and choose the level of care that minimizes the total cost of accidents and care, $X_{i}=\operatorname{argmin} x_{i}+p_{i}\left(x_{i}\right) L$.

The timing of the model is as shown in Figure 1. Potential injurers, victims, and the courts are initially symmetrically uninformed about whether injurers are good or bad risks. Potential injurers then have the opportunity to learn their type. Potential injurers may then purchase liability insurance. We consider the case where the potential injurer can provide verifiable proof of their type to the insurance company. We also consider cases where the potential injurer can provide less information to the insurance company. After the potential injurers have decided whether or not to buy insurance, they choose their expenditure on care, which is assumed to be observable. Nature then determines whether an accident occurs. If an accident occurs, the courts costlessly determine the injurer's type and apply the negligence rule to determine liability.

\section{Negligence rules}

A uniform negligence rule applies the same standard of due care to all potential injurers.

\footnotetext{
${ }^{4}$ We are making an assumption about timing, namely that care is observed ex ante so that the premium can depend on care. However, under the alternative assumption that care is only observed ex post in the event of an accident, the indemnity can depend on the level of care.
} 
Definition 1 Under the uniform negligence rule, an injurer is negligent if $x<X_{I}$, where

$$
X_{I}=\operatorname{argmin} x_{I}+p_{I}\left(x_{I}\right) L .
$$

This is the well-known Hand Rule: injurers are negligent if the social burden of the untaken precaution is less than the expected social harm. Thus, injurers are fully liable for damages to victims and the standard of care minimizes the total cost of accidents and care. Shavell (1982) shows that, if injurers are identical and victims are risk neutral, the uniform negligence rule achieves the first best outcome. Also, since potential injurers meet the standard of care and are never negligent, they bear no risk. It is interesting to note that Shavell (2000) does not consider this particular version of the negligence rule in his analysis.

Crocker and Doherty assume that the courts use an individualized negligence rule. The individualized negligence rule sets different standards of care, $X_{G}$ and $X_{B}$, for good risks and bad risks.

Definition 2 Under the individualized negligence rule, an injurer is negligent if they are of risk type $i$ and $x_{i}<X_{i}$, where

$$
X_{i}=\operatorname{argmin} x_{i}+p_{i}\left(x_{i}\right) L \quad i=B, G .
$$

Again, injurers are fully liable for damages to victims, the standards of care minimize the total cost of accidents and care for each type of potential injurer, as well as in the aggregate. Potential injurers meet the appropriate standard of care and bear no risk. The argument in Shavell (1982) shows that, if victims are risk neutral, then the individualized negligence rule achieves the first best outcome. Observe that the assumptions on the loss probabilities imply that $X_{G}<X_{I}<X_{B}$. Finally, whether an individual is negligent depends only on the rule employed and the individual's care, not on whether the individual is informed.

Under the uniform negligence rule, good risks are required to expend too much on care to meet the standard, while bad risks are required to expend too little. This increases the total social cost of accidents plus expenditure on care relative to the individualized negligence rule. As noted by Schwartz (1998, p. 559), "In the great majority of instances, however, the legal standard requires the injurer not to take the care that is optimal for that injurer, but rather the care that would be taken [by] the 'reasonable person'." This leads to the question of why the uniform rule would be used. As Landes and Posner (1987, pp. 123-131) point out, the inefficiency of the uniform rule must be compared to the information costs of determining individualized standards of care. As they observe (p. 127) "In types of cases where the information costs of departing from the average-man standard are low because the gap between the 
average individual's due care standard and that of the individual defendant is large and palpable, the courts, as predicted, recognize a different standard." The widespread use of the reasonable person standard implies that, in most cases, these information costs are high. As a widely used treatise on torts puts it: "The standard of conduct which the community demands must be an external and objective one, rather than the individual judgment, good or bad, of the particular actor; and it must be, so far as possible, the same for all persons, since the law can have no favorites" (Keeton et al., 1984, pp. 173-174).

\section{Value of information}

We measure the value of information as the expected increase in expected utility from becoming informed. Let $V$ denote expected utility and let $z=(p, q, x)$ be the arguments of the potential injurers expected utility function. Let $\hat{z}_{i}$ maximize expected utility for an individual of type $i=B, G, I$, subject to any relevant constraints. Then the value of information is the gain in expected utility from becoming informed

$$
\mathcal{J}=\lambda_{G} V_{G}\left(\hat{z}_{G}\right)+\lambda_{B} V_{B}\left(\hat{z}_{B}\right)-V_{I}\left(\hat{z}_{I}\right)
$$

We assume that individuals become informed if the value of information is positive.

\section{Uniform negligence rule}

Crocker and Doherty (2000) show that, when the standard of negligence is individualized, risk averse potential injurers will choose to remain uninformed and will purchase full insurance. We now consider the question of whether potential injurers will become informed about their type and whether a market for liability insurance will arise when the negligence rule is uniform, that is, under a reasonable person standard.

We initially assume that, if they become informed, potential injurers can provide verifiable proof of their type to the insurer. Uninformed potential injurers meet the standard of care and have utility $U\left(W-X_{I}\right)$ and have no demand for insurance. If injurers become informed and learn that they are bad risks, then they meet the standard of care and have utility $U\left(W-X_{I}\right)$. If there is a demand for liability insurance, then it must come from informed good risks.

Proposition 1 Assume a uniform negligence standard and that insurers can verify informed potential injurers' risk-type. Then the necessary and sufficient 
condition for $(a)$ good risks to fully insure $(q=L)$ and expend $X_{G}$ on accident prevention and for $(b)$ the value of information to be positive is that

$$
X_{I}>X_{G}+p_{G}\left(X_{G}\right) L .
$$

Proof (a) If injurers learn that they are good risks, then they may be better off to choose a lower level of care and insure against the resulting liability exposure. Since they can verify their type, the premium is actuarially fair, $p_{G}(x) q$. The informed good risks then fully insure and choose the level of care, $X_{G}$, to minimize their total cost of accidents plus expenditure on care. This yields utility $U\left(W-X_{G}-p_{G}\left(X_{G}\right) L\right)$. Informed good risks are better off purchasing insurance if, and only if, Eq. (5) holds. (b) Then the value of information is

$$
\begin{aligned}
\mathcal{J} & =\lambda_{G} U\left(W-X_{G}-p_{G}\left(X_{G}\right) L\right)+\lambda_{B} U\left(W-X_{I}\right)-U\left(W-X_{I}\right) . \\
& =\lambda_{G}\left[U\left(W-X_{G}-p_{G}\left(X_{G}\right) L\right)-U\left(W-X_{I}\right)\right]
\end{aligned}
$$

Then the value of information is positive if, and only if, the inequality in Eq. (5) holds.

That is, the value of information is non-negative if the cost of complying with the negligence standard is greater than the cost of being negligent plus the cost of insurance. If the inequality in Eq. (5) holds, then potential injurers become informed and the informed good risks buy liability insurance. If the inequality in Eq. (5) is reversed, the cost of complying with the negligence standard is greater than the cost of being negligent plus the cost of insurance. If so, then potential injurers remain uninformed, spend $X_{I}$ on accident prevention and there is no demand for liability insurance. Also, whether the inequality in Eq. (5) holds depends only on the objective proportions of good and bad risks, their respective loss probabilities and the amount of damages (which determine $X_{G}$ and $\left.X_{I}\right)$, but does not depend on potential injurers' subjective attitudes toward risk.

If risk type is verifiable, then lack of information about risk is not an essential part of the demand for liability insurance. Suppose that, instead of being initially uninformed, all potential injurers are initially exogenously informed about their risk type. Then the bad risks meet the standard of care and the good risks insure if, and only if, the inequality in Eq. (5) holds. That is, if Eq. (5) holds, the outcome is the same as when potential injurers are initially informed about their risk of an accident and insurers can verify their type. 
The insurance policy bought by the good risks is also attractive to the uninformed and to the bad risks. The insurance company was able to offer the policy since it could identify the good risks and exclude others from purchasing the policy. For example, suppose that the insurance company cannot verify whether potential injurers are informed or uninformed. Then, since it cannot exclude the uninformed, the insurance company faces an adverse selection problem and must take this into account in designing the policy. That is, the policy must satisfy the self-selection constraint

$$
V_{I}\left(p_{G}(x) q, q, x\right) \leqslant U\left(W-X_{I}\right) .
$$

We let $\hat{q}_{G}$ denote the equilibrium level of coverage and $\hat{x}_{G}$ denote the equilibrium expenditure on care by informed good risks.

Proposition 2 Assume a uniform negligence standard and that insurers cannot verify whether potential injurers are informed (i.e., cannot verify whether potential injurers are informed good or bad risks or uninformed). Then the necessary and sufficient condition for $(a)$ good risks to less than fully insure $\left(\hat{q}_{G}<L\right)$ and increase expenditure on accident prevention $\left(\hat{x}_{G}>X_{G}\right)$ and for (b) the value of information to be positive is that Eq. (5) holds.

Proof (a) Observe that if Eq. (5) holds, then the expression in Eq. (6) is positive and the self-selection constraint is binding. Let $\hat{q}_{G}$ and $\hat{x}_{G}$ maximize $V_{G}\left(p_{G}(x) q, q, x\right)$ subject to the self-selection constraint. Observe that if $q=L$ and $x=X_{G}$, the constraint is violated. Since the constraint is binding, we must have $\hat{q}_{G}<L$, and, since the good risks are less than fully insured, they increase expenditure on care, $\hat{x}_{G}>X_{G}$. Letting $\hat{z}_{G}=\left(p_{G}\left(\hat{x}_{G}\right) \hat{q}_{G}, \hat{q}_{G}, \hat{x}_{G}\right)$, informed good risks obtain expected utility $V_{G}\left(\hat{z}_{G}\right)$. Since $V_{G}\left(\hat{z}_{G}\right)>V_{I}\left(\hat{z}_{G}\right)=U\left(W-X_{I}\right)$, informed good risks are better off purchasing insurance. (b) The value of information is

$$
\begin{aligned}
\mathcal{J} & =\lambda_{G} V_{G}\left(\hat{z}_{G}\right)+\lambda_{B} U\left(W-X_{I}\right)-U\left(W-X_{I}\right) \\
& =\lambda_{G}\left[V_{G}\left(\hat{z}_{G}\right)-U\left(W-X_{I}\right)\right]
\end{aligned}
$$

Since $V_{G}\left(\hat{z}_{G}\right)>V_{I}\left(\hat{z}_{G}\right)=U\left(W-X_{I}\right)$, the value of information is positive.

To prove necessity, observe that if the inequality in Eq. (5) is reversed, then $U\left(W-X_{I}\right)>U\left(W-X_{G}-p_{G}\left(X_{G}\right) L\right)>V_{G}\left(\hat{z}_{G}\right)$. Then good risks are better off if they do not purchase insurance and the value of information is negative.

Alternatively, insurance companies may be able to distinguish informed from uninformed potential injurers, but may be unable to determine whether 
informed injurers are good or bad risks. Then the self-selection constraint becomes.

$$
V_{B}\left(p_{G}(x) q, q, x\right) \leqslant U\left(w-X_{I}\right) .
$$

Then a result analogous to Proposition 2 holds. We let $\tilde{q}_{G}$ denote the coverage and $\tilde{x}_{G}$ denote the expenditure on care.

Proposition 3 Assume a uniform negligence standard and that insurers can verify whether potential injurers are informed but cannot verify their type. Then the necessary and sufficient condition for $(a)$ good risks to less than fully insure $\left(\tilde{q}_{G}<L\right)$ and increase expenditure on accident prevention $\left(\tilde{x}_{G}>X_{G}\right)$ and for $(b)$ the value of information to be positive is that Eq. (5) holds.

This follows from the same argument as Proposition 2. Now observe that if the self-selection constraint for the informed bad risks in Eq. (9) is binding, then the self-selection constraint for the uninformed in Eq. (7) must also hold as an inequality. Then we have (a) $\tilde{q}_{G} \leqslant \hat{q}_{G}$ and $\tilde{x}_{G} \geqslant \hat{x}_{G}$ with at least one strict inequality and, letting $\tilde{z}=\left(p_{G}\left(\tilde{x}_{G}\right) \tilde{q}_{G}, \tilde{q}_{G}, \tilde{x}_{G}\right)$, we have (b) $V_{G}(\hat{z})>V_{G}(\tilde{z})$.

The inability of insurers to distinguish individuals' information status or to distinguish informed individuals' type makes the good risks worse off since $U\left(W-X_{G}-p_{G}\left(X_{G}\right) L\right)>V_{G}(\hat{z})>V_{G}(z)$. This fact, combined with a binding selfselection constraint in either Eq. (7) or Eq. (9), implies that the inequality in Eq. (5) must hold. Therefore, the inequality in Eq. (5) is a necessary condition for the value of information to be positive. Conversely, if the inequality in Eq. (5) is reversed, then regardless of the information disclosure environment, the value of information is always negative and there is no demand for liability insurance.

\section{Conclusions}

In this paper, we address the question of whether potential injurers' lack of information about the risks that they face is sufficient to create a demand for liability insurance under a uniform negligence rule. That is, we assume the liability rule is the simple rule of negligence and that the negligence rule is perfectly enforced by the courts. We also assume that potential injurers, victims, and the courts are initially uninformed about potential injurers' risk of accidents. The issues are then (1) whether potential injurers will choose to learn about their characteristics and (2) whether they will buy liability insurance.

Under a uniform negligence rule, the same standard of care applies to all individuals (i.e., the "reasonable person" rule). As long as certain reasonable conditions are met, the value of information is positive under the uniform 
negligence rule. Thus, uninformed individuals choose to become informed about the risks they face and the outcome is the same as if individuals know their characteristics to begin with. The demand for insurance then comes from informed parties whose privately optimal level of care is below the negligence standard. For these individuals, the cost of being negligent and purchasing insurance is less than the cost of complying with the standard of care.

It is interesting to compare our results to those of Crocker and Doherty, since we reach essentially opposite conclusions. In our analysis, insurance is purchased by informed individuals, while in their analysis insurance is purchased by uninformed individuals. Crocker and Doherty assume an individualized negligence rule. They argue that the uninformed face "classification risk," the risk arising from the ex ante randomness of the cost of meeting the relevant negligence standard. In particular, individuals are worse off if they learn that they are high risk and must meet a high standard of care. Buying insurance allows uninformed individuals to hedge the classification risk. We assume a uniform negligence standard or reasonable person rule - the prevalent negligence standard in the United States. Under the reasonable person standard, the negative component of classification risk is eliminated. Individuals who learn that they are high risk can continue to meet the reasonable person standard and are not made worse off as a result of becoming informed.

Finally, we should point out that insurance is socially beneficial. Under a uniform negligence rule, the fact that the value of information is positive means that potential injurers are better off to become informed. Informed good risks, who purchase insurance are strictly better off while informed bad risks are neither better nor worse off. Since informed good risks choose to be negligent, insurance increases the number of accidents. However, victims are compensated if the accident is caused by a good risk, so that potential victims are better off.

\section{Acknowledgements}

Earlier versions of this paper were presented at the American Risk and Insurance Association, Western Risk and Insurance Association and Risk Theory Society meetings and at the University of Oregon and we thank session and seminar participants for helpful comments. We thank the anonymous reviewer and Keith Crocker (the Editor) for helpful comments that have substantially improved the paper. Thistle's research was supported by the Nevada Insurance Education Foundation.

\section{References}

Bond, E. and Crocker, K. (1991) 'Smoking, skydiving and knitting: The endogenous categorization of risks in insurance markets with asymmetric information', Journal of Political Economy 99: $177-200$. 
116

Brown, J. (1973) 'Toward an economic theory of liability', Journal of Legal Studies 2: 323-350.

Crocker, K. and Doherty, N. (2000) 'Why people buy liability insurance under the rule of simple negligence', in M.R. Baye (ed) Industrial Organization, Amsterdam: Elsevier Science.

Crocker, K. and Snow, A. (1992) 'The social value of hidden information in adverse selection economies', Journal of Public Economics 48: 317-347.

Doherty, N. and Thistle, P. (1996) 'Adverse selection with endogenous information in insurance markets', Journal of Public Economics 63: 83-102.

Ehrlich, I. and Becker, G. (1972) 'Market insurance, self-insurance and self-protection', Journal of Political Economy 80: 623-648.

Keeton, W.P., Dobbs, D.B., Keeton, R.E. and Owens, D.G. (1984) Prosser and Keeton on Torts, 5th edn. St. Paul: West Publishing Co.

Landes, W. and Posner, R. (1987) The Economic Structure of Tort Law, Cambridge, MA: Harvard University Press.

Ligon, J. and Thistle, P. (1996a) 'Information asymmetries and informational incentives in monopolistic insurance markets', Journal of Risk and Insurance 63: 434-459.

Ligon, J. and Thistle, P. (1996b) 'Consumer risk perception and information in insurance markets with adverse selection', Geneva Papers on Risk and Insurance Theory 21: 191-210.

Schwartz, W.F. (1998) 'Legal standards of care', in P. Newman (ed) The New Palgrave Dictionary of Economics and the Law, Vol. 2, New York: Stockton Press.

Shavell, S. (1982) 'On liability and insurance', Bell Journal of Economics 13: 120-132.

Shavell, S. (1987) Economic Analysis of Accident Law, Cambridge, MA: Harvard University Press.

Shavell, S. (1992) 'Liability and the incentive to obtain information about risk', Journal of Legal Studies 21: 259-270.

Shavell, S. (2000) 'On the social function and the regulation of liability insurance', Geneva Paper on Risk and Insurance Issues and Practice 25: 166-179.

\section{About the Authors}

Vickie Bajtelsmit, J.D., Ph.D., is a professor and Chair of the Department of Finance and Real Estate at Colorado State University where she has taught insurance and finance since 1991.

Paul Thistle, Ph.D., is Professor of Finance at the University of Nevada Las Vegas, where he has taught insurance since 1999.

Disclaimer We retain the responsibility for any remaining errors. 